\title{
MODOS E PRÁtICAS LEGAIS NA EXECUÇÃO DOS SERVIÇOS PÚBLICOS
}

\author{
MANOEL DE OLIVEIRA FRANCO SOBRINHO \\ Professor Catedrático de Direito Administrativo na \\ Universidade Federal do Paraná
}

É axiomático que, no contexto dos sistemas jurídicos, a expressão e o que está expresso, a forma e o conteúdo dos fenômenos, os atos e os fatos coincidentes, se conjugam numa simbiose indisfarçavel e de profundos efeitos para a determinação da relação jurídica.

Quando alertamos para a existência de um direito de "realidades" e não para um direito de "abstrações", apenas estamos querendo demonstrar que o que é público não deixa de ser positivo, ou seja, que não há compartimentos estanques no complexo das instituições jurídicas.

A verdade assenta numa já velha proposição de J. P. RAMOS em que se diz com rara clarividência que o Direito Administrativo tem como fim a necessidade jurídica de estabelecer por meio de regras justas e flexíveis, adaptadas à realidade social, a melhor organização jurídica institucional ${ }^{1}$.

De plano, não se pode mais afirmar o que HAURIOU afirmava no começo do século, ou melhor, que todos os Estados assumem ou possuem funções administrativas, mas que nem todos condicionamse a um regime administrativo ${ }^{2}$. Onde quer que hoje em dia haja organização administrativa, há por certo regime administrativo. Cabendo apenas ao estudioso investigar as excelências ou as falhas que levam às imprecisões formais ou de conteúdo programático.

(1) Juan Pablo Ramos - ENSAYO JURÍdICO Y SOCIAL SOBRE LA CONCESION DE SERVICIOS PÚBLICOS - Introducción - Buenos Aires, 1937 - página 3.

(2) Maurice Hauriou - PRECIS DE DROIT ADMINISTRATIF ET DE DROIT PUBLIC - Paris, 1933 - página 1. 
Diante do fato e da lei, não procedem os exageros doutrinários. Tão pouco, a busca dos elementos comparados. Nem mesmo, as regras informadoras. Eis que, nos regimes administrativos, prevalecem os condicionamentos géo-políticos. A.s instituições são como elas são e não como queremos que elas sejam.

\section{$\S 10^{\circ}$ - OS MODOS DE GESTÃO}

Com isso, naturalmente, não se pretende desmerecer a influência do direito comparado. Mas considerá-lo apenas na sua importância como direito-fonte, isto é, em razão das peculiaridades ou singularidades que atuam na formação do direito interno de cada nação.

Os modos de gestão, para efeito das práticas administrativas, correspondem às normas de direito interno. As origens históricas institucionais valem naquilo que se harmonizam com a organização política e social. Organização que também é administrativo.

As especulações doutrinárias jamais serviram ao direito na sua expressão de vida real. Sobretudo quando as teorias não se adaptam a circunstâncias fáticas. Um dos equivocos que mais frequentemente se equacionam, dentro das fronteiras dos sistemas jurídicos, é precisamente aquele que conduz à controvérsia no tocante ao conhecimento exato da problemática administrativa.

Não cabe ao jurista, diante do direito estrangeiro e dos seus meios expressionais, deixar-se impressionar por situações que muitas vezes são transitórias. Nem considerar, num dado momento, quais os piores ou melhores instrumentos de atuação administrativa.

Qualificadoramente, em qualidade, os instrumentos a adotar são os aconselhados pelo sistema. Modos de administração não são modismos administrativos. Tanto assim que, usando o poder público, na sua capacidade de escolha, essa ou aquela figura jurídica, nada mais está fazendo que, prosurar o caminho certo do procedimento melhor adequado.

\section{$\S 2 .^{\circ}$ - A LEI COMO REGRA E MEDIDA}

Permitindo o direito positivo, não resta o que discutir. 0 mé. todo mais simples de conhecimento é aquele melhor aproximado do chamado realismo jurídico. Método que limita-se, pura e simplesmen te, ao estudo dos valores efetivos caracterizantes da ordem jurídica constituída. 
Seria inajustável à realidade o poder administrativo caso não pudesse buscar suporte material no direito positivo. Assim porém não acontece. Considerando que as concepções formalistas são as que melhor aderem à natureza das sociedades jurídicas.

Sem dúvida estamos diante de conceitos não contraditórios e de razão prática. Conceitos em função da ratio practica que orientam a ordem jurídica e estabelecem as normas que prescrevem a conduta administrativa. Surgindo a lei como a regra e a medida do que deve ser feito ${ }^{3}$.

Ao prestar serviços, o Estado, admite técnicos que não se limitam à processos fechados. Nas causas concretas estão os fatores básicos do surgimento das pessoas administrativas ${ }^{4}$. Tanto faz, por. tanto, acolher-se o processo privado como adotar-se critérios públicos.

No fundo o que importa é o serviço público necessário, essencial, de caráter programático. Compatibilizado, sem distorsões, com os sistemas jurídicos. Amparado, nas implicações, pela ordem jurídica positiva. Mas dependente, na atividade, do sentido-fim de exploração economica ou social.

\section{$\S 3 .^{\circ}$ - ADMINISTRAÇÃO NA ORDEM POSITIVA}

Irrelevante torna-se, portanto, uma orientação que não seja objetiva na prática administrativa. Ou que permita controversias inconceituais impróprias. Uma orientação que ao invés de harmonizar traga no seu bojo a tônica da incerteza jurídica.

Daí porque não convencem as proposições doutrinárias especulativas. As tomadas de posição conflitantes com a ordem positiva. Temerárias quando pretendem inovar através situações não adequa. das. Dizendo o que o Estado deve fazer ou não deve, apesar dos permissivos legais e institucionais.

Toda a ordem positiva está ao dispor da Administração pública. O direito privado também integra como elemento categorizado a relação administrativa. As potestades não excluem jamais a partici. pação do indivíduo na atividade estatal. Participação que é de cola. boração e de integração ${ }^{5}$.

(3) Hans Kelsen - A JUSTIÇA E O DIREITO NATURAL - trad. port. - Coimbra, 1963 - conceito de razão prática em Tomás de Aquino - página 117.

(4) Celso Antônio Bandeira de Mello - PRESTAÇÃO DE SERVIÇOS PúBLICOS E ADMINIS. TRAÇÃO INDIRETA - São Paulo, 1973 - página 88.

(5) Essa legítima posição jurídica não é de agora. Já preocupou especialistas como André 
Mesmo a vontade unilateral gera obrigações. Os condicionamentos civis ou privados obrigam também na área de atuação administrativa. A questão, tal como está posta no direito privado, em têrmos se coloca no direito público ${ }^{6}$. Dentro, porém, de prioridades finalisticas.

No fim-objetivo, repita-se novamente, reside o elemento que dá fisionomia às pessoas administrativas. Sem com isso, no entanto, descaracterizarem-se as pessoas na sua origem, forma e conteúdo. Pessoas que, uma vez criadas, passam a integrar organicamente a administração estatal.

\section{$\S 4 .^{\circ}$ - AO ESTADO CABE A ESCOLHA DA PESSOA JURídICA}

Nada de estranho sucede com as novas ou velhas pessoas administrativas quando surgem no mundo do Direito Administrativo. $E$ nada se justifica, na doutrina, para a tirada de conclusões fora do largo contexto legal e de sistema.

Como observamos, as fundações continuam como fundações, sejam quais sejam os fins pretendidos. O regime é o mesmo tanto na esfera privada como na ordem administrativa. A distinção que se possa fazer entre uma e outra entidade fundacional, expressa tão sòmente uma natureza peculiar.

Igualmente acontece com as sociedades mistas na sua específica função singularizada. E também, sem nenhuma dúvida, com as empresas públicas e as autarquias. Ao Estado, de sua parte, cabe a escolha da pessoa melhor apropriada às finalidades perseguidas.

Jamais, no entanto, poder-se-á dizer, que uma ou outra forma tenha caído em desuso. Todas elas, sem exceção, servem à administração indireta naquilo que é considerado como essencial em razão de fim pretendido. De resto, são autênticas e legítimas as distintas opções legais.

A valiosa lição de BIELSA vem de longa data ${ }^{7}$. Marcando, no que diz com os novos fenômenos, a herança que o Direito Adminis-

Buttgenbach, Paul Cère, Carlo Girola, Agustin A. Gordillo, Silvio Lessona, Oreste Rannelletti, Guido Zanobini e Rafael Bielsa. Contudo, anote-se, não a identidade de um mesmo pensamento orientador, mas um mesmo sentido de definição com respeito à problemática de estrutura administrativa.

(6) Francisco Soto Nieto - VOLUNTAD UNILATERAL GENERADORA DE OBLIGACIONES Informacion Jurídica - n.o 313 - Madrid, 1972.

(7) Rafael Bielsa - RELACIONES DEL CODIGO CIVIL CON EL DERECHO ADMINISTRATIVO A Buenos Aires, 1923. 
trativo recebeu do Direito Civil ${ }^{8}$. Não permitindo, que essa herança recebida na sua pureza original, apareça desvirtuada fale aos exagêros publicísticos.

\section{$\S 5 .^{\circ}$ - FORMAS ADEQUADAS E PARTICIPAÇÃO}

Diga-se de passagem que as autarquias falham ou falharam, não poucas vezes, por excesso de tutela e quebra de autonomia, ou então pela rigorosa dependência administrativa, quando na verdade impor se devia com severidade o largo princípio da responsabilidade.

No Brasil foi a intervenção não discriminada que levou as entidades autarquicas às crises internas constantes de funcionamento, transformando-as em simples departamentos estatais. Talvez, o mesmo fato, na sua evidência, tenha influído nas sociedades de economia mista.

Mas são teorias, especulações teóricas, que divergem de uma concepção formalista e positiva do direito. Assinalando posições curiosas que em nada se justificam, mas que no entanto se conflitam com a ordem indispensável aos sistemas jurídicos.

E incontestável que de há muito está se notando, na esfera dos direitos internos, um crescente crescimento da presença do Estado na vida econômica, não apenas como regulador de atividades produtivas e financeiras, mas como também de atuação direta (ou indireta) como empresário.

Em matéria de serviço público, sem dúvida, alguns empreendimentos por seu vulto, não permitem às pessoas privadas assumiram isoladas os riscos do negócio econômico. Encontradas as formulas adequada, num regime que seja ou não de participação, os fins estão assim resguardados.

\section{$\S 6 .^{\circ}$ - O INSTRUMENTO ADOTADO NO PROCESSO CRIADOR}

São novas dimensões e novas perspectivas que busca a moderna Administração. Dessarte, no campo jurídico terá o Estado como missão específica e objetivo fundamental aquilo que se poderia talvez considerar como interêsses públicos e privados convergentes.

(8) Consulte-se: André Hauriou - UTLLIZAÇÃO EM DIREITO ADMINISTRATIVO DAS REGRAS E PRINCÍPOS DO DIREITO PRIVADO - RDA - Vol. I, Fasc. II; Rui Cirne Lima - DIREITO PRIVADO - RDA - Vol. XXVI/19; Carlos Medeiros Silva - PESSOAS JURÍDICAS DE DIREITO PÚBLICO E DE DIREITO PRIVADO - parecer - RDA - Vol. III/434; $M$. Seabra Fagundes - DA CONTRIBUIÇÃO DO CÓDIGO CIVIL PARA O DIREITO ADMINISTRATIVO - RDA - Vol. 78/1; e ainda, Rui Cirne Lima - O CÓDIGO CIVIL E $O$ DIREITO ADMINISTRATIVO - RDA - Vol. 62/1. 
Nada mais é válido senão o que resultar do estudo conjugado do instrumenio específico utilizado pelo poder público e do processo de elaboração (no sentido da boa técnica) para a criação das mais diferentes pessoas administrativas.

Dois pontos exigem atenção do hermeneuta: aquele que diz com - instrumento adotado e aquele outro que diz com o processo criador. Não possibilitando assertivas que possam desmerecer este ou aquele instrumento, este ou aquêle modo de proceder dentro de faculdades legais.

Considere-se que não há razão de ser para o que BILAC PINTO apontou no concernente às sociedades de economia mista (9). $O$ advento das modernas empresas públicas jamais trouxeram ao Estado outra preocupação senão aquela de operações outras melhor capazes de realizações práticas.

No mesmo equívoco incidiu J. CRETELLA JÚNIOR tratando das autarquias ${ }^{10}$, afirmando que tal modêlo jurídico tem os seus dias contados ou parece estar superado em nossa época. É preciso não confundir, mas simplesmente distinguir. Eis que os meios aqui correspondem aos fins.

\section{$\S 7 .^{\circ}$ - AS ESTRUTURAS ORGÂNICAS}

Traga-se à colação, com respeito às autarquias, o alentado estudo-tese de CELSO ANTONIO BANDEIRA DE MELLO ${ }^{11}$. Não bastando, busque-se pelo que traduz da realidade administrativa, o trabalho-ensaio em torno das melhores figuras que servem aos meIhores propósitos de descentralização institucional e jurídicos. Observando o Estado na divisão dos seus poderes, a Administração pela função dividida, é precisamente a forma que explicita e determina a conceituação física e jurídica de qualquer órgão pblico.

Só pela forma adotada o órgão se individualiza ou personifica qualificando a sua posição no direito e a sua categoria na estrutura do Estado. É pelo ato legal de criação do órgão que as categorias ganham conteúdo, atividade funcional e também corpo no conjunto orgânico estatal (13).

(9) Ver: O DECLínIO DAS SOCIEDADES DE ECONOMIA MISTA E O ADVENTO DAS MODERNAS EMPRESAS PÚBLICAS in ESTUDOS SOBRE A CONSTITUIÇÃO BRASILEIRA - Fundação Getúlio Vargas - Rio de Janeiro, 1954.

(10) EMPRESA PÚBLICA - São Paulo, 1973 - página 270.

(11) Consultar: NATUREZA E REGIME JURÍDICO DAS AUTARQUIAS - São Paulo, 1967.

(12) Celso Antcnio... PRESTAÇÃo DE SERVIÇO... - ob. cit. - São Paulo, 1973.

(13) Manoel de Oliveira Franco Sobrinho - INTRODUÇÃO À TEORIA DO ÓRGÃO NO DIREITO 
A tendência não é outra que aquela hoje aceita e consagrada: a da racionalização do Estado e do poder administrativo, a da racionalização dos meios para a realização efetiva dos serviços públicos essenciais, a da racionalização dos modos de execução na atividade administrativa.

Para tal efeito servem bem as fundações, as sociedades de economia mista, as empresas públicas e as autarquias. Cada qual, como pessoa, exercitando fins e objetivos programados. Cada entidade, na sua expressão de força jurídica, tornando possível ao Estado prestar serviços públicos.

\section{$\S 8^{\circ}$ - MISSÃO FUNCIONAL E PERSONALIDADE JURÍDICA}

Podendo-se falar em missão funcional ou em regime peculiar de competência especializada, todas essas pessoas administrativas nominadas: integradas na estrutura estatal ou na ordem jurídica positiva, passam a servir ao interesse público qualificado em têrmos de objetivos coletivos.

A questão é, sobretudo, de personalidade jurídica. Personalidade que, pelo traço fisionomico fundamental, distingue as pessoas administrativas umas das outras. Personalidade que está inclusa na própria natureza do instituto. Sem embargo, todavia, das origens no processo histórico.

Nas autarquias, prevalecem os elementos autonômos "que se impõem por virtude própria"14. Não se impondo, na figura jurídica, simplesmente a vontade estatal, mas a necessidade do serviço. Necessidade esta aliada à capacidade de administrar-se. De bastar-se num regime de autonomia.

Está claro que com as fundações o mesmo não sucede. Nem com as empresas públicas ou as sociedades de economia mista. Eis que as autarquias surgem de um desdobramento do poder público estatal, ao passo que as demais figuras aparecem manifestas na sua mais legítima pureza institucional.

Os regimes é que são diversos, basicamente diferentes. Acaso existam conotações não fazem elas características semelhantes e nem sequer assemelhadas. Basta afirmar que, nem por serem pessoas administrativas, sejam as fundações, empresas públicas ou sociedades mistas, pessoas públicas.

ADMINISTRATIVO - Separata de laRevista de Ciências Administrativas - Ano XIV n. 034 - La Plata, 1971.

(14) Celso. Antônio - NATUREZA E REGIME JURídICO DAS AUTARQUIAS - cit. - pag. 220. 


\section{$\S 9 .^{\circ}$ - A PRESTAÇÃO INDIRETA DE SERVIÇOS}

Por favor, não se façam confusões estéreis. A excelência das autarquias não pertence ao tráfico das tendências positivas ou negativas do pensamento doutrinário. Nem tão pouco o que representam as fundações, ou as sociedades de econômia mista, e rambém as modernas empresas públicas.

São figuras reais, não abstrações jurídicas. Existem, apesar do nosso gesto ou inclinação especulativa. O problema continua vivo na sua realidade e na sua dimensão jurídica. Não discutido nas suas implicações temáticas, mas equacionado nas suas proporções conjunturais ${ }^{15}$.

As autarquias, todavia, já mais sentidas pela compreensão unânime da doutrina ${ }^{16}$. Alargadas no processo administrativo descentralizador. Colaborando com o Estado inclusive no processo de descencentração geográfica ou territorial. Como pessoas até marcadas de supremacia.

No direito brasileiro, o Decreto-lei n. ${ }^{\circ} 200$, que já anteriormente noutra oportunidade comentamos, mesmo com a alteração trazida pelo Decreto-lei n. ${ }^{\circ} 900$, acabou com as tergiversações. Integrador da estrutura administrativa, consolidou de plano a prestação indireta de serviços.

Efetivamente, pelo desempenho de serviço público, aparecem todas as nominadas expressões jurídicas figurativas, como pessoas administrativas. Quer se criem ou formem, na Administração indireta, no regime de direito privado ou no caso as autarquias por força de personalidade pública.

\section{$100^{\circ}$ - REGRAS JURÍDICAS E CAPACIDADE}

A questão a apreciar, portanto, limita-se ao âmbito da permitida atividade administrativa. À preexistência de regras jurídicas de caráter funcional, ou seja, de competência jurisdicional. Regras que se vinculam à capacidade jurídica, ou melhor, à condição de existência da pessoa.

(15) Sobre òs autarquias, procure-se a leitura de dois importantes trabalhos do professor Juan Carlos Luqui: 1) REGIMEN JURíDICO DE LA UNIVERSIDAD OFICIAL - com um estudo de Rafael Bielsa Aires, 1968; 2) AUTONOMIA Y AUTARQUIA UNIVERSITAT - La universidades - Buenos Aires, 1968; 2) AUTONOMIA Y AUTARQUIA UNIVERSITAT - La Ley - Tomo 146 - pag. 1.033 - Buenos Aires, 1972.

(16) Basta o que iá ensinaram grandts administrativistas como Orlando, Santi Romano, Salandra, D’Alessio, Cine Vitta, Raggi, Cammeo, Bodda e Ugo Forti. Senão tstes outros como no Brasil Tito Prates da Fonseca, Mario Masagão, Themistocles Cavalcanti, Rui Cisne Lima, Cretella Júnior, A. B. Cotrim Neto, Meirelles Teixeira, Hely Lopes Meirei- 
Nas fundações, não esqueçamos, a tese é uma só. O caráter da fundação, como figura jurídica, manifesta-se de pronto nos regimes jurídicos. Numa linha clássica de hábil adequamento. Valendo a relação administrativa em razão da validade do procedimento e do elemento vontade pública.

Não fosse a relação de administração tanto peculiar ao direito público como ao direito privado, então os valores personalizados poderiam aparecer sob outros aspectos fisionômicos. O processo de direito público jamais se conflita na ordem pública com o processo de direito privado.

Ressalte-se, pela importância da relação existente e permanente, que o que importa é a "categoria jurídica utilizada"17. O sentido formal da manifestação de vontade administrativa. A causa ou o fim do motivo legal. Nunca, sem dúvida, as diferenciações conceituais ou de pessoa.

Qualquer regime legal, diz naturalmente com o interesse público peculiar. Não se podendo descaracterizar um instituto privado só porque o fim é público. Tal posição, se adotada, contraria a unidade do direito, opõe-se ao direito como sistema normativo ou de princípios ordenativos.

\section{$\S 110^{\circ}-$ As PESSOAS ADMINISTRATIVAS}

Aceite-se, como a mais correta posição, a explicada por RUI CIRNE LIMA, ampliando porém um conceito que possui não mais estreitas limitações doutrinárias, pois as pessoas administrativas apontando uma "adequação específica à atividade de administração pública que thes é peculiar"18, instituídas por lei para a execução de serviços de interesse público, não continuam como eram antes adstritas apenas já àquelas poucas de natureza política.

Na sua extensão dominam a relação de administração, operando na constância através de instrumentos próprios ou organismos de ação. Relação que, na realidade, determina e informa a organiza-

les, Luiz Delgado e Carlis Medeiros Silva' Não falando dos Bandeira de Mello, Oswaldo Aranha e Celso Antônio. Mas ainda lembrando, nos estrangeiro, Horácio Heredia, Bielsa, Balsavibaso, Ranelletti, Zanobini e Manuel Maria Diez.

(17) Lafayete Pondé - A VONTADE PRIVADA NA FORMAÇÃO OU NA EFICÁCIA DO ATO ADMINISTRATIVO - RDA - n.0 63/18, Manoel de Oliveira Franco Sobrinho - REGIME JURIDICO DAS FUNDAÇÕES NO DIREITO ADMINISTRATIVO BRASILEIRO - Ciências Administrativas - La Plata, 1972; Manoel de Oliveira Franco Sobrinho - AS FUNDA. ÇÕES E O DIREITO ADMINISTRATIVO - RDA - n.0 100/1.

(18) Ver: SISTEMA DE DIREITO ADMINISTRATIVO BRASILEIRO - Introdução - Vol. 1 Porto Alegre, 1953 - pág. 139. 
ção interna da pessoa administrativa ${ }^{19}$. Mas, é, todavia, na diversificação das pessoas que reside 0 " $x$ " da equação jurídica. Ou o aparecimento, na estrutura geral administrativa, quer das autárquias e sociedades de economia mista, quer das empresas públicas e das fundações. Num desenvolvimento que só 0 interêsse público acautela ${ }^{20}$.

De uma maneira ou de outra, só o interêsse público é preponderante para a especialidade do serviço público. Como veremos, pouco mais adiante, antes da lei está o fato. $O$ fato como realidade e como verdade, obrigando a Administração a conhecer de algumas ou muitas necessidades coletivas, de alguns ou muitos problemas que afetam a própria organização administrativa.

A problemática é, portanto, não só de vontade pública, mas de evidência no contexto social. Não sobra ao Estado, diante da técnica do proceder jurídico, senão as opções aconselhadas pelo sistema. Nada podendo inventar, mas podendo buscar as formas nos tradicionais institutos já consagrados pela história nos diferentes regimes de organização administrativa.

\section{$\S 120^{\circ}$ - INTERESSSE PÚBLICO E NEGóCIO JURÍDICO}

Falando de negócio jurídico, numa expressão terminológica não muito convincente mas realistica, MICHELE CANTUCCI dá com largueza a definição que se espera para as espécies de atividade da Administração ${ }^{21}$, recomendando porém a necessidade de qualificação dos meios que levam à proteção de interesse público.

O importante, contudo, ainda que assim não lembre o professor de Siena, está em se determinar na qualificação das pessoas, o que seja negócio em direito público ou negócio em direito privado. Até onde possa ir a Administração para materialmente efetivar o interesse público. O problema, no entanto, não ganha dificuldade ante a premência do fato acontecido. Ou simplesmente diante de fatores que se fazem positivos para a ordem social ou econômica.

E essa é, explicitamente, uma função normativa da lei. Da norma, por assim falar, depois que se adotam critérios formais e finalísticos. Da lei e da norma que estabelecem, em consequência, cate-

(19) Rui Cirne Lima - ob. cit. - Vol. 1 - pág. 143.

(20) 'E hoje ccmo ontem, a multiplicidade dos fins que, na comunidade política, se propõem à atividade da administração pública, provoca e estimula, quase incessantemente a multiplicação das pessoas administrativas, sem função política'”. (Cirne Lima - ob. cit. - Vol. I - página 54.

(21) Consultar: L'ATTIVITA DI DIRITTO PRIVADO DELLA PUBBLICA AMMINISTRAZONE Padova, 1942 - página 47. 
gorias que se afirmam condicionadas, ou então vinculadas, às conveniências da Administração.

Diga-se, sem temor de equívocos doutrinários, atendendo principalmente o que pretendem as empresas públicas e as sociedades econômicas, que o conceito de negócio jurídico jamais pode considerar-se estranho ao direito público (22), tendo em conta os elementos que atuam inspirando a vontade estatal.

Logo, essa vontade, não é bem livre, está sujeita à escolhas de procedimento e de processo. Sendo livre, no entanto, no que diz com as pessoas administrtivas, para em razão do fim impor a forma jurídica, para em razão da causa determinar a qualidade da figura administrativa.

\section{$\S 13^{\circ}$ - O FATO E A LEI}

O elemento condição-fato (conditio facti) aparece tão logo se faça presente em certo serviço público indispensável. O elemento condição-lei (condictio iuris) vem depois para concretar a obrigação que nasce da realidade administrativa, econômica ou social, vinculando o Estado ao interesse público.

Compete, sem dúvida, à Administração, sentir o serviço público quando manifesto, ou seja, quando imposto pelo interesse geral. Daí a relevância que a doutrina francesa concedeu ao fenômeno serviço público: com DUGUIT defendendo o intervencionismo e HAURIOU a institucionalização ${ }^{23}$.

São duas posições de admirável objetividade crítica e conceitual. Acolhendo, uma mesma tese através de uma linha distinta de pensamento, a tese bastante simples de que os modos e os meios pertencem à livre escolha da Administração, guardados os pressupostos de oportunidade, poder jurídico e conveniência.

No entanto, não é bom esquecer, mesmo diante da liberação dos modos e dos meios, e onde a discrição administrativa permite ao Estado indicar a pessoa jurídica adequada, o que ANDRÉ BUTTGENBACH chama de serviço público orgânico ${ }^{24}$. Possibilitando, destarte, no problema quando surge, uma noção material que não se conflita com o conceito jurídico.

(22) Michele Canticci - cb. cit. - página 54.

(23) Léon Duguit - TRAITE DE DROIT CONSTITUTIONNEL - Vol. I - Paris, 1921/1926 páginas 223/439; Maurice Hauriou - PRÉCIS DE DROIT ADMINISTRATIF ET DE DROIT PUBLIC - Préface - Paris, 1936.

(24) Ver tHÉORIE GÉNÉRALE dE MOdES DE GESTION DES SERVICES PUBLICS EN BELGIQUE - Bruxelles - Paris, 1952 - página 74 e segts. 


\section{$\S 140^{\circ}$ - FACULDADES OPCIONAIS E NÃO DISCRICIONARIEDADE}

Por certo, as faculdades opcionais da Administração não the dão discricionariedade quanto aos modos e aos meios de se criarem pessoas administrativas para a execução de serviços públicos, tidos como indispensáveis ou mesmo prioritários. São faculdades ordenadas, disciplinadas, regulamentadas, ainda que pese a primacialidade estatal, a supremacia do poder administrativo.

Acreditando no processo de direito privado, a Administração nada mais faz que submeter-se à tutela de regimes jurídicos, ou seja, aos sistemas que mantém a ordem jurídica consagrada. Nisto, evidentemente, não vai nenhuma novidade, pois as figuras quando são criadas não escapam das rígidas determinantes legais e positivas.

A lista disso, é que se harmonizam, os dois aspectos de procedimento: o público com respeito aos fins-objetivos, e o privado pelo modus faciendi que não comporta outras alternativas senão as inspiradas pelas técnicas comuns e também positivas.

A única justificável exceção de origem aparece nas autarquias ${ }^{25}$. Nunca com os organismos autonômos, entidades privadas de fins públicos, instituídas com a finalidade específica de executar determinado programa, como pode ser uma fundação, uma empresa pública ou uma sociedade de economia mista.

Aliás, há de se entender, que a tarefa de execução de um serviço, não foge da natureza da pessoa jurídica. Para isso, é que elas se qualificam, frente às variações de atividade administrativa. E para permitir, na flexibilidade, o cumprimento das obrigações.

\section{$\S 150^{\circ}$ - PERSONALIDADE E CAPACIDADE}

Quando se lança mão de recurso das fundações, o que se quer é uma entidade fundacional capaz de atender à peculiares circunstâncias de serviço. Um organismo apropriado que possa dar resposta à determinada promoção administrativa de interesse coletivo. Com atribuição expressa de personalidade e de capacidade jurídicas.

(25) Prevalecem nas autarquias alguns fundamentais elementos diferenciados, à saber: ser órgão indireto do Estado, ter capacidade especifica de direito público, possuir interesses que são concernentes aos da administração, agir com liberdade e no exercício de funções administrativas, realizar adminisfiação pública em nome próprio, fazer descentralização por colaboração, ter fins de serviço público, e, ter autonomia pelo fato de receber delegação de poderes e outorga de funções. Além do mais, vincular-se ao Estado, pela tutela administrativa. 
No dizer de MARCELO CAETANO, com formação singular, onde a capacidade é sempre determinada pela ordem jurídica, mas capacidade que "pode ser mais ou menos ampla, limitar-se ao direito privado ou estender-se também à esfera do direito público"26. Precisam€nte aqui, nas premissas, guarda o instituto a sua virtualidade vital e potencial como pessoa.

Os mesmos argumentos informativos valem para as empresas públicas criadas sob a égide do poder estatal. Bastando para tais pessoas a sua forma específica de direito, o limite na extensão dos poderes de gestão e a incidência do vínculo relacional com o Estado. O que varia, substancialmente, contudo, é o ponderável elemento finalistico de linha de ação econômica ${ }^{27}$.

Ressaivados os motivos de estrutura e funcionalidade, as sociedades de economia mista muito se assemelham às empresas públicas. O que se quer para uma ou outra pessoas não é propriamente uma distinção demarcatória específica, mas disposições administrativas que pela tipologia definam em razão do fins as características internas ${ }^{28}$.

Daí a considerar, para ambas as espécies de pessoas, o ato formador, a composição do capital e a estrutura personalizada. Não importam, no affaire, que alguns fins possam transcender aos objetivos imediatos da Administração. Toda verdade tem suporte na natureza da relação administrativa. Relação que se exterioriza dos objetivos visados na criação.

\section{$\S 160^{\circ}$ - AS DISTINÇÕES NA OPÇÃO DA FORMA LEGAL}

Prevalecem, nas citadas pessoas administrativas, inclusive em parte também nas fundações, alguns pressupostos que são de natureza autárquica. Levando, não poucas vezes, a doutrina à equivocos não procedentes. Baralhando os conceitos ou tendendo para impropriedades substânciais.

Os modos e as práticas legais, tendo em mira a execução de serviços públicos, trazem à confronto numa unidade de propósitos, condições que se tornam comuns e generalizantes. Tais como os

(26) Caetano - DAS FUNDAÇõES - Subsídios para a interpretação e reforma da legislação portuguesa - Lisboa, 1962 - página 54.

(27) Urbano Valero Agundez - LA FUNDACION COMO FORMA DE EMPRESA - Valladolid, 1969.

(23) Themistocles Cavalcanti - EMPRESAS PÚBLICAS e SOCIEDADES DE ECONOMIA MISTA - Revista de Ciência Política - FGV - Volume 7 - n.o 4 - Rio de Janeiro, 1973. 
objetivos visados no ato de criação, a organização peculiar interna e a participação do Estado na formação da pessoa administrativa ${ }^{29}$.

As distinções, contudo, são orgânicas na opção da forma legal adequada. Mas numa medida e grau de participação que evidencia antes a incidência do critério administrativo e jurídico sôbre o econômico ${ }^{30}$. Não obtante, sem dúvida, as implicitas determinações de política econômica.

Ainda que as empresas públicas, no momento, sejam as pessoas mais comumente aconselhadas, isto não quer dizer que as outras não tenham a sua grande importância no quadro da Administração indireta. Tanto assim que permanecem como instrumentos variáveis na variada atividade administrativa.

O que conduz à confusão. considerando horizontalmente o problema dos estabelecimentos públicos no seu entendimento mais amplo, é a aưonomia como regra de existência nas pessoas jurídicas. Nos sistemas legais, ou regimes jurídicos, no entanto, a autonomia não surge como mera condição eletiva.

Observadas as pessoas administrativas em função de administração, ou então na gestão dos interesses peculiares de serviço, é a exủensão da autonomia legal, as fronteiras até onde possam atuar, a presença de prerrogativas que cobrem os controles externos na sua eficácia fiscalizadora.

\section{$\S 170^{\circ}$ - EXPANSÃO DOS INSTRUMENTOS OPERACIONAIS}

Certo que a preocupação em torno das empresas públicas absorve hoje mais largo interêsse doutrinário ${ }^{31}$. Justifica-se, tal posição de interêsse, pela expansão dos instrumentos operacionais em áreas que superam o direito interno para alcançar projeção internacional ${ }^{3: 2}$.

(29) "Todos esses elementos conduzem à afirmação de que existe uma estrutura de direito privado, não obstante certos privilégios e prerrogativas, de que podem gozar e de preceitos legais especiais relativos à natureza dos seus funcionários e ao preenchimento de certos cargos de direção" (Themistocles Cavalcanti - trab. cit. - lec. cit. - página 49).

(30) Agustin A. Gordillo - EMPRESAS DEL ESTADO - Buenos Aires, 1966 - página 17.

(31) Consultar: A. Brewer Carlas - LAS EMPRESAS PúBLICAS EN EL DERECHO COMPARADO - Caracas, 1967; H. Hanson - PUBLIC ENTERPRISE AND ECONOMIC DEVELOPMENT Lcndres, 1966; G. Cáballero Sierra - LAS ENTIDADES DESCENTRALIZADAS EN EL DERECHO ADMINISTRATIVO - Bogotá, 1972; R. B. Garrido Valenzuela - LAS EMPRESAS ESTATALES - Santiago do Chile, 1966; L. Solari - L'EMPRESA PUBLICA NEL TRATATTO ISTITUTIVO DELLA COMUNITÁ ECONOMICA EUROPEA - Milano, 1965; Eduardo WHITE - EMPRESAS MULTINACIONALES LATIOAMERICANAS - México, 1973.

(32) Ver: Félix Peña, Eduardo White, Susana C. do Zaduendo - EMPRESAS MULTINACIONALES LATINOAMERICANAS - Esfudio de los aspectos jurídicos de la Associación Internacional de Empresas en América Lałina - ALALC - Montevideo, 1973. 
Nas fundações, no estágio atual em que se encontram, as dimensões não passam de locais, regionais ou nacionais. Nas sociedades de economia mista, as perspectivas atingem talvez relações de maior profundidade e de alcance econômico. Quanto às autarquias, não vão além da conjuntura nacional.

Nem por isso, os diferentes modos e práticas, não deixam, pelas distintas linhas de ação, de apresentar peculiaridades essenciais de conteúdo programático. Todos eles servem ao Estado e à Administração. Inscrevem-se no direito positivo e público de cada nação. E cada qual, na sua maneira jurídica.

Verifique-se, na complexa problemática de índole internacional, que a ação estatal não se faz fora dos sistemas jurídicos. Mas respeitando o que dizem as regras jurídicas internas. No tocante às alternativas de entendimentos associativos internacionais, vigem duas constantes: uma de forma da pessoa urídica, outra de objetivos que se consagram através de convênios, acôrdos ou simplesmente de coniratos de adesão ${ }^{33}$.

No Brasil, por exemplo; como na maioria das legislações estrangeiras, não se prevê a ação internacional economica ou de negócio. Mas mesmo que não se preveja, esse tipo de ação extrapolando fronteiras, se completa por força de interesses comuns que se integram, cu de interesses que visam a integração de importantes setores da economia pública.

\section{$\S 180^{\circ}$ - AS FIGURAS JURÍDICAS DE ASSOCIAÇÃO INTERNACIONAL}

No que que respeita à posição brasileira, já definida no contexto do sistema, o que importa reflete-se em alguns aspectios importantes:

a) na existência de uma estrutura empresarial múltipla nos seus devidos fins legais específicos;

b) numa estrutura que passou a ser mobil no ativamento das relações internas e também exteriormente;

c) mobilidade que oferece ao regime empresarial público uma variada tipologia de unidades assemelhadas;

d) tipologia que não se prende a uma única forma legal porque assume diversidade na formulação jurídica.

Como já lembramos, no acerto entre nações, em razão da posi-

(33) Manoel de Oliveira Franco Sobrinho - REGIME LEGAL DAS EMPRESAS PúBLICAS NO BRASIL - Ação Internacional - Trabalho informativo realizado para o Instituto para la integracion de América Laşina (INTAL) - Buenos Aires, 1973. 
ção legal brasileira, o que se obejtiva são projetos comuns em formas conjuntas. Uma associação, por assim dizer, vinculada aos sistemas legais binacionais ou então multinacionais ${ }^{34}$.

Nas espécies brasileiras há a preocupação: de recursos financeiros, de bens de capital e de recursos tecnológicos. Tudo naturalmente conforme as distintas formas permitidas de associação. Eis que não se pode, nem se deve, estabelecer critérios exclusivos de entendimento, pois os possíveis critér ios assentam na viabilidade dos projetos e na possibilidade de participação econômica.

De momento, na esfera das pesquisas comparadas, as implicações ao menos em tese, partem de uma convenção. Nascem de uma linha mestra de acôrdo na ação econômica de comércio internacional. Mediante a qual, as partes legítimas interessadas, estabelecem têrmos que informam reciprocidade.

\section{$\S 19 .^{\circ}$ - A ESCOLHA DA FORMA JURÍDICA NO BRASIL}

A escolha da forma jurídica no Brasil é essencial, mas não é o elemento mais importante e fundamental. São os fins que definem a natureza da empresa pública, não necessariamente os elementos formativos. Daí porque, numa atuação ordenativa geral, não há o Estado de prescindir dos outros tipos de pessoas como as fundações e as sociedades de economia mista.

Correto que as empresas públicas tenham assumido projeção de proporções não esperadas. Ou que, em termos de programação de política econômica, buscassem o amparo do processo de direito privado, e, além desse amparo, tomassem, para sí, as excelências das sociedades por ações ou mistas.

Tanto essa projeção é verdadeira, que no conceito sentido de ação empresarial pública, no Brasil, não se disținguem basicamente as sociedades por ações, as mistas ou as empresas públicas propriamente chamadas.

São elas, as empresas públicas, as formas de tipo privado, apesar do contrôle e da tutela, economicamente mais abertas e flexiveis. Pelas quais, o Estado, na sua soberania, intervem ou pode intervir na ordem econômica. E praticar atos que possibilitem rentável ação internacional ${ }^{35}$.

(34) Oliveira Franco Sobrinho - trab. cit. !- INTAL.

(35) ‘Nos objetivos finalidades) e funções específicas, reside a possibilidade de ação internacional, através naturalmente das próprias empresas ou de subsidiárias formadas com a adesão do pessoas estrangeiras. À não ser que haja proibição expressa ou taxativa, a 
Não vamos dizer que a experiência em têrmos jurídicos não seja a melhor aconselhada. Desconcentrar e descentralizar, no âmbito da Administração, é a única solução para os problemas, ainda não equacionados, e que surgem do inevitável desenvolvimento. Sobretudo com os sucessos da ciência e da tecnologia, submetendo o Estado à situações forçadas de real comportamento administrativo.

\section{$\S 200^{\circ}$ - CONCLUSÃO}

Toda e qualquer atividade administrativa é objetiva, racional e formal. Desconcentração ou descentralização não são apenas simples questões propostas à curiosidade do pensamento doutrinário. São fenomenos sim, e que pertencem à lei científica da divisão do trabalho administrativo.

Mesmo nas Administrações centralizadas a problemática assume evidência indisfarçável. Principalmente quando se trata de órgãos, serviços e competências decisórias. Sobretudo quando nos regimes políticos o Estado se organiza em círculos de atividade jurisdicional e geográfica.

Sem reservas, diga-se, são as leis naturais, de geo-política, de geo-economia, atuando na formação da vontade estatal. Obrigando - Estado para bem viver, desconcentrar-se para funcionar. Impondo à Administração critérios não só de hierarquização, mas de transferência de poderes e deveres.

Pela descentralização as atividades administrativas passam a executar-se repartidamente, consoante os meios jurídicos adequados e os fins públicos essenciais programados. Integrando a estrutura estatal, as várias unidades cumprem finalidades assinaladas no ordenamento jurídico.

Com apoio nos institutos clássicos que informam as fundações as empresas e as sociedades comerciais, e também de certa maneira as autarquias, o Estado busca modos e práticas legais para a execução dos serviços público. Não desmerecendo o direito como unidade, sistema e regime natural.

livre atuação é sempre permitida. Está claro, no entanto, pelo menos no Brasil, que as variações na legislação economica e comercial, cambial e financeira, não constituem fatôres negativos, mas motivantes dos acôrdos que se fizerem necessários, o que então já existem" (Manoel de Oliveira Franco Sobrinho - Trab. cit. - Ação Internacional Informe ao INTAL). 